\title{
Evaluation of Methods for Measuring Particulate Matter Emissions from Gas Turbines
}

\author{
Andreas Petzold, ${ }^{*,+}$ Richard Marsh, ${ }^{\neq}$Mark Johnson, ${ }^{\S}$ Michael Miller," Yura Sevcenco, ${ }^{\ddagger}$ David Delhaye, ${ }^{\perp}$ \\ Amir Ibrahim, ${ }^{+}$Paul Williams, ${ }^{\#}$ Heidi Bauer, ${ }^{\nabla}$ Andrew Crayford, ${ }^{\ddagger}$ William D. Bachalo, ${ }^{\bigcirc}$ and David Raper \\ ${ }^{\dagger}$ DLR, Institut für Physik der Atmosphäre, Oberpfaffenhofen, 82234 Wessling, Germany \\ ${ }^{\ddagger}$ School of Engineering, Cardiff University, Cardiff CF24 0DE, U.K. \\ ${ }^{\S}$ Rolls-Royce plc, Derby DE24 8BJ, U.K. \\ "QinetiQ, Cody Technology Park, Farnborough Hants GU14 OLX, U.K. \\ ${ }^{\perp}$ ONERA, 92320 Chatillon, France \\ ${ }^{\#}$ Centre for Atmospheric Science (CAS), University of Manchester, Manchester M13 9PL, U.K. \\ ${ }^{\nabla}$ Vienna University of Technology, 1060 Vienna, Austria \\ ${ }^{\circ}$ Artium Technologies, Sunnyvale, California 94086, United States \\ -Manchester Metropolitan University, Manchester M15GD, U.K. \\ Supporting Information
}

ABSTRACT: The project SAMPLE evaluated methods for measuring particle properties in the exhaust of aircraft engines with respect to the development of standardized operation procedures for particulate matter measurement in aviation industry. Filter-based off-line mass methods included gravimetry and chemical analysis of carbonaceous species by combustion methods. Online mass methods were based on light absorption measurement or used size distribution measure-

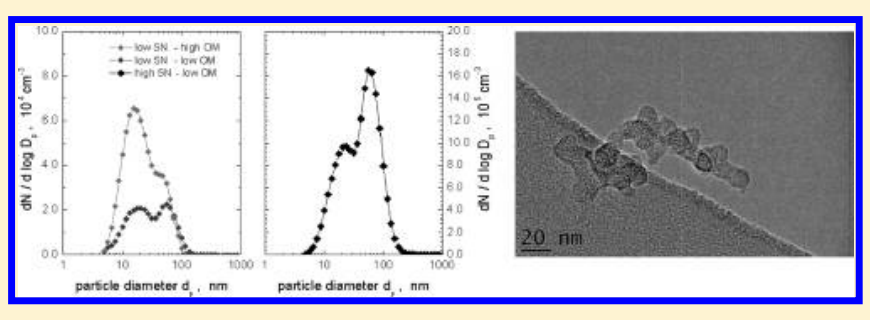
ments obtained from an electrical mobility analyzer approach. Number concentrations were determined using different condensation particle counters (CPC). Total mass from filter-based methods balanced gravimetric mass within $8 \%$ error. Carbonaceous matter accounted for $70 \%$ of gravimetric mass while the remaining $30 \%$ were attributed to hydrated sulfate and noncarbonaceous organic matter fractions. Online methods were closely correlated over the entire range of emission levels studied in the tests. Elemental carbon from combustion methods and black carbon from optical methods deviated by maximum 5\% with respect to mass for low to medium emission levels, whereas for high emission levels a systematic deviation between online methods and filter based methods was found which is attributed to sampling effects. CPC based instruments proved highly reproducible for number concentration measurements with a maximum interinstrument standard deviation of $7.5 \%$.

\section{INTRODUCTION}

Concerns on potential impacts of aviation particulate matter (PM) emissions on Earth's climate and human health ${ }^{1}$ has stimulated the development of new measurement methodologies for PM emission certifications for aircraft engines. ${ }^{2} \mathrm{PM}$ emissions consist of volatile particles (do not exist in the condensed phase at $T=350{ }^{\circ} \mathrm{C}$ ) which form in the expanding and cooling plume downstream the engine, and of nonvolatile combustion particles (exist as particulates at $T=350{ }^{\circ} \mathrm{C}$ ) which form inside the engine. ${ }^{3}$ One key property governing particles' impact on climate via contrail formation and aerosol cirrus interaction is the number of nonvolatile particles ${ }^{4}$ while studies focusing on the impact of aircraft emissions at ground on air quality show the importance of sub-20 nm sized volatile particles. ${ }^{5-7}$

The engine emissions databank of the International Civil Aviation Organization ICAO (www.caa.co.uk/) lists emission factors for gaseous species in units of gram per $\mathrm{kg}$ of burnt fuel.
PM emissions, however, are reported as smoke number ( $\mathrm{SN}$ ), which relates the darkening of particle-loaded filters to the mass of deposited PM. ${ }^{8} \mathrm{SN}$ does not measure mass, nor is it intended to include volatile particulate matter. New methodologies for replacing the $\mathrm{SN}$ method focus on engine exit plane measurements of nonvolatile particles only because combustion-related particles are closely linked to engine properties. Volatile PM is excluded in the current stage because they form downstream the engine exit, and their formation depends crucially on fuel properties and ambient conditions.

An overview of techniques available for measuring nonvolatile PM emissions from aircraft engines was prepared by the SAE

\footnotetext{
Received: November 26, 2010

Accepted: March 10, 2011

Revised: $\quad$ March 9, 2011

Published: March 22, 2011
} 
E-31 Aircraft Exhaust Emissions Measurement Committee. ${ }^{2,9}$ Building on this method review this committee prepares aerospace recommended practice (ARP) documents for future standardized measurement methods for nonvolatile PM. The key purpose of the study SAMPLE (sampling and measurement of aircraft particulate emissions) which is funded by the European Aviation Safety Agency (EASA) is to evaluate potential methods for gas turbine emission measurements and to provide information on instrument applicability and method characteristics under real-world conditions corresponding to engine certification measurements. $^{10}$

\section{EXPERIMENTAL APPROACH}

2.1. Rig Description. Particle emissions were generated by a gas turbine engine simulator composed of a combustor and a unit to simulate a 3-shaft turbine section (so-called hot end simulator; HES). This particular assembly was developed and successfully applied during the EU project PARTEMIS. ${ }^{11}$ The representativeness of HES PM emissions for aircraft gas turbine emissions was evaluated. ${ }^{12}$ Here, the HES served as a robust source for simulated gas turbine exhaust PM. Aviation grade kerosene Jet A-1 with fuel sulfur content (FSC) of 0.030 wt- $\%$ (weight-\%) was used.

The exhaust gas flow was transported through temperaturecontrolled pipes which were kept above $160{ }^{\circ} \mathrm{C}$ on gas analysis lines and controlled at $70{ }^{\circ} \mathrm{C}$ on heated sections of PM sampling lines. The exhaust gas was pretreated in a hot dilution system for removing the majority of volatile PM. The hot dilution system was constructed of a DEKATI pressurized dilution air heater and ejector diluter (DI-1000) which was operated at $400{ }^{\circ} \mathrm{C}$ and diluted the sample by a factor of 10:1. The hot diluter was followed by a $9.525 \mathrm{~mm}$ (3/8 in.) line of $2655 \mathrm{~mm}$ length kept at $360{ }^{\circ} \mathrm{C}$. At the downstream end of the heated line a Palas VKL 10-E stainless steel injection diluter was operated. The overall dilution ratio was on average $34.6 \pm 3.9$, indicating a $1 \sigma$-variation of the average value of approximately $11 \%$. Details of the HES set up and the sampling line set up are given in the Supporting Information (SI).

In total three operation conditions were selected. Condition 1 (C1: low particulates-low organic matter) represents the baseline condition with nominal particulates and organic matter loading. Condition 2 (C2: low particulates-high organic matter) represents a typical engine loading for low load operation of an aircraft waiting at the gate. Condition 3 (C3: high particulates-low organic matter) refers to a condition typical for high load in preparation of takeoff. The aim of selecting the three conditions was to provide measurable differences in the composition of the particulates emitted from the HES. Of particular interest was the difference in emissions for cases of varying organic matter (volatile, semivolatile and nonvolatile) and nonvolatile elemental carbon contributions to PM.

2.2. Measurement Methods. Nonvolatile PM mass methods are divided into three approaches: (i) gravimetric methods which measure total particulate mass (TM); (ii) carbon burnoff methods which measure total carbon (TC), organic carbon (OC), and elemental carbon (EC); (iii) optically based methods which are sensitive to the light absorbing black carbon (BC) fraction of PM, making them decidedly appropriate for measuring nonvolatile combustion particles because nonvolatile carbon and light-absorbing carbon are closely linked. Table S1 of the SI compiles the list of applied PM methods and instruments. The uncertainty values stated in the following refer to errors of the analysis method, but do not include sampling errors.

Gravimetry uses glass fiber filters (Whatman GF/C) for exhaust particle sampling that show a filtration efficiency of $>99 \%$ in the size range $10 \mathrm{~nm}<d_{\mathrm{p}}<500 \mathrm{~nm}$ relevant for PM emitted from gas turbines. Sampled PM is analyzed gravimetrically by weighing the filter before and after loading. The gravimetric methodology was based upon techniques described in ref 13 . Prior to weighting, the samples were gently heated, removed from the oven, placed in a desiccator, and left in there to cool to room temperature. This method was adopted to avoid as much as possible any water and gaseous compounds being absorbed by the filter matrix during sampling. Prior to any measurements on filter samples a known mass was weighed 10 times to exercise the balance and determine confidence limits. Known errors associated with this technique are about $\pm 10 \%$.

Filter samples for 2-step combustion (2-SC) were collected on preconditioned quartz fiber filters $(47 \mathrm{~mm} \varnothing$, Pallflex-Tissue quartz, Pall Life Sciences). During sampling the flow through the filters was fixed by a critical orifice providing a constant volumetric flow rate of $10.7-11.0 \mathrm{~L} \mathrm{~min}^{-1}$. 2-step combustion ${ }^{14}$ without $\mathrm{HCl}$ fumigation analyses the carbon content of $\mathrm{PM}$ in a two-step combustion process where $\mathrm{OC}$ is removed at $340{ }^{\circ} \mathrm{C}$ in pure $\mathrm{O}_{2}$. The remaining carbon, defined as $\mathrm{EC}$, is then determined as $\mathrm{CO}_{2}$ evolving at $1000{ }^{\circ} \mathrm{C}$ (TC error $8 \%$; EC, OC error $20 \%{ }^{15}$ ). Total carbon (TC) is measured from the same sample in a separate singlecombustion step at $1000{ }^{\circ} \mathrm{C}$ in $\mathrm{O}_{2}$ while $\mathrm{OC}$ is obtained from TC-EC. Besides carbon, organic matter (OM) contains also oxygen and hydrogen which can be approximated by $\mathrm{OM} \cong 1.20 \times$ $\mathrm{OC}$ for fuels with an $\mathrm{O} / \mathrm{C}$ ratio of less than $1.0 \mathrm{wt}-\% .{ }^{16}$ For the carbonaceous fraction of PM, OC is the appropriate property, whereas $\mathrm{OM}$ has to be considered if total mass is targeted.

Aerosol absorption photometry analyzes the modification of filter optical properties as transmittance or reflectance caused by the light-absorbing particles deposited on the filter. The principal measure of any absorption photometer is the aerosol absorption coefficient $\sigma_{\text {ap }}$, given in units of $\mathrm{m}^{-1}$. The conversion of an absorption coefficient into a $\mathrm{BC}$ mass concentration requires the assumption of a mass-specific absorption cross-section, $\mathrm{B}_{\mathrm{BC}}$. Multi-angle absorption photometry (MAAP) is an improved version of absorption photometers which uses a multi angle absorption photometer approach combined with a radiation transfer code ${ }^{17}$ to analyze the modification of radiation fields in the forward and back hemispheres of a glass-fiber filter caused by deposited particles. The THERMO model 5012 MAAP uses $B_{\mathrm{BC}}=6.6 \mathrm{~m}^{2} \mathrm{~g}^{-1}$ at $\lambda=630 \mathrm{~nm}$ which was determined from calibration studies. ${ }^{17}$ This value is in accordance with $B_{\mathrm{BC}}=7.5$ $\mathrm{m}^{2} \mathrm{~g}^{-1}$ at $550 \mathrm{~nm}$ proposed for fresh BC. ${ }^{18}$ The standard deviation of the error in $\mathrm{BC}$ mass concentration is $12 \% .{ }^{17}$ In terms of reproducibility the standard deviation is $3 \%{ }^{19}$

Laser-induced incandescence (LII) measures the thermal emission (incandescent light) from particles heated by a pulsed laser to temperatures in the $2500-4500 \mathrm{~K}$ range. ${ }^{20}$ Similar to absorption photometry, LII is highly selective for BC only and cannot be used for measuring TM. LII data is converted from the volume fraction to mass concentration by applying the particle material density for EC of $1900 \mathrm{~kg} \mathrm{~m}^{-3.20}$ In terms of bias, it depends on the knowledge of the absorption function, as does the MAAP. In terms of reproducibility, the standard deviation is $3 \%$ as measured by operating two instruments in parallel.

PM emitted from a gas turbine is composed of elemental carbon, organic matter and inorganic species like sulfate $\left(\mathrm{SO}_{4}\right)$. 
Besides gravimetry, the sum of chemical components offers an alternative for total mass determination. The selected approach follows version 3 of the First Order Approximation (FOA3) for estimating particulate matter emissions from certified commercial aircraft engines. ${ }^{21}$ The contributing species are determined directly like EC, estimated from measurement data like OM, or estimated from fuel properties like sulfur-containing compounds. The sulfate content of TM originates from the fuel sulfur which is converted to particulate sulfate with an average efficiency $\varepsilon=$ 2.4wt-\%. ${ }^{3,21}$ With FSC $=0.030 \mathrm{wt}-\%\left(0.30 \mathrm{~g} \mathrm{~kg}^{-1}\right)$ for the fuel burned, the sulfate emission index $\mathrm{EI}_{\mathrm{SO} 4}$ in $\mathrm{g}$ per $\mathrm{kg}$ of fuel burn is

$$
E I_{\mathrm{SO} 4}=\mathrm{FSC} \times \varepsilon \times \frac{\mathrm{MW}_{\mathrm{SO} 4}}{\mathrm{MW}_{\mathrm{S}}}
$$

with molecular weights $\mathrm{MW}_{\text {species }}$ of respective species. The core flow $Q_{\text {core }}$ of air through the aircraft engine combustor in $\mathrm{m}^{3}$ per $\mathrm{kg}$ of fuel burn is required to calculate the exhaust mass concentration of sulfate from the respective emission index. The value of $Q_{\text {core }}$ is calculated from the combustor air-to-fuel ratio AFR by ${ }^{21}$

$$
Q_{\text {core }}=0.776 \times \mathrm{AFR}+0.877
$$

This approximation matches the experimental conditions within $\pm 10 \%$, see SI.

As is known from the gravimetric analysis of particle samples from diesel engines, ${ }^{22}$ sulfate exists in its hydrated form as $\left(\mathrm{H}_{2} \mathrm{SO}_{4} \cdot 4.5 \mathrm{H}_{2} \mathrm{O}\right)$ for conditions applicable to gravimetry. This fraction of sulfate-associated water has to be considered in the assessment of the sum of the chemical components. Combining all contributions, the mass concentration of hydrated sulfate in the exhaust flow is

$$
\begin{aligned}
\mathrm{H}_{2} \mathrm{SO}_{4} \cdot 4.5 \mathrm{H}_{2} \mathrm{O}= & \text { FSC } \times \varepsilon \times \frac{\mathrm{MW}_{\mathrm{H} 2 \mathrm{SO} 4}}{\mathrm{MW}_{\mathrm{S}}} \times \frac{1}{Q_{\text {core }}} \\
& \times\left[1+\frac{4.5 \mathrm{MW}_{\mathrm{H} 2 \mathrm{O}}}{\mathrm{MW}_{\mathrm{H} 2 \mathrm{SO} 4}}\right]
\end{aligned}
$$

Finally, total particulate matter is calculated from the sum of single components as

$$
\mathrm{TM}_{\mathrm{SUM}}=\mathrm{OM}+\mathrm{EC}+\mathrm{H}_{2} \mathrm{SO}_{4} \cdot 4.5 \mathrm{H}_{2} \mathrm{O}
$$

The overall error of this approximation method is estimated as $22 \%$ based on $8 \%$ uncertainty for the TC determination and on $20 \%$ uncertainty for the estimation of hydrated sulfate. The latter value is based on the fact that adding or subtracting one $\mathrm{H}_{2} \mathrm{O}$ molecule leads to a variation in hydrated sulfate mass by $\pm 10 \%$.

Number concentrations in the exhaust gas were measured by three different models of condensation particle counters (CPC). The applied instruments differed significantly in the minimum

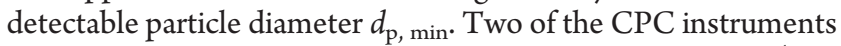
are manufactured by TSI Incorporated, Shoreview, MN, (TSI model $3760, d_{\mathrm{p}, \min }=14 \mathrm{~nm}$; TSI model $\left.3010, d_{\mathrm{p}, \min }=10 \mathrm{~nm}\right)$, one CPC is produced by GRIMM Aerosol Technik, Germany (GRIMM model 5.400, $d_{\mathrm{p}, \min }=5 \mathrm{~nm}$ ). Similar instruments were tested for their applicability to measuring automotive engine exhaust PM. ${ }^{23}$ Since the CPC based instruments cannot distinguish between volatile and nonvolatile particles, volatile particle removal requires thermal pretreatment of the sample as described in Section 2.1 and in the SI.

Particle size distributions were measured by means of electrical mobility spectrometers. ${ }^{24}$ Two different models were applied:

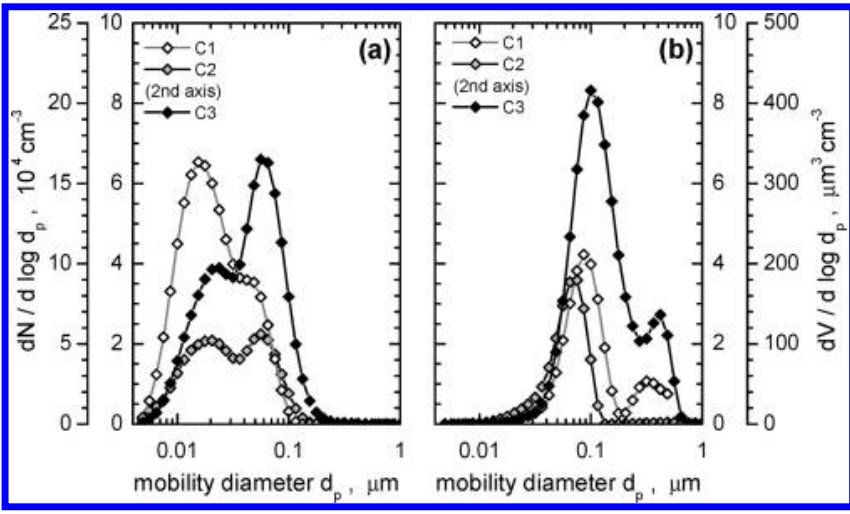

Figure 1. Particle size spectra for all investigated conditions measured with a DMS500 in terms of number (a) and volume (b); the fraction of particles larger than $10 \mathrm{~nm}$ in diameter is $>90 \%$ for investigated conditions $\mathrm{C} 1-\mathrm{C} 3$.

DMS500 manufactured by CAMBUSTION, UK, and TSI model 3090 EEPS, manufactured by TSI Inc. Differential mobility spectrometers separate charged particles according to their electrical mobility. They are widely used in the measurement of diesel engine emissions ${ }^{25}$ and aircraft engine emissions. ${ }^{5}$ The mobility diameter was measured with compensation made for the number of charges as suggested in the data processing respective to the DMS500 and the EEPS. The maximum size of particles detectable by a DMS500 is $1 \mu \mathrm{m}$ in diameter.

The electrical aerosol detector $\mathrm{EAD}^{26}$ reports a measurement of total particle length which corresponds to the sum of all particle diameters present in the probed volume. The method employs diffusion charging of aerosol particles and their subsequent detection by a sensitive electrometer. This diffusion charging produces a nearly linear relationship between particle diffusion diameter and the number of unit charges acquired by particles in the $10 \mathrm{~nm}-1 \mu \mathrm{m}$ size range. ${ }^{27,28}$ Normalizing the EAD signal to the total particle number concentration measured by a CPC may provide another potential method for measuring an average particle size. ${ }^{27,28}$

2.3. Data Reduction. For Condition 1, two tests (Run 1, Run 2) were performed, whereas for Condition 2 and Condition 3, single tests were conducted. Respective runs lasted $03 \mathrm{~h} 40 \mathrm{~min}$ (C1-R1), 02 h $20 \mathrm{~min}$ (C1-R2), 06 h (C2), and 02 h $30 \mathrm{~min}$ (C3). The following numbers of filter samples were analyzed: C1-R1: three samples each for gravimetry and 2-step combustion; C1R2: one sample each for gravimetry and 2-step combustion; C2: three samples for gravimetry, 5 samples for 2-step combustion; C3: three samples for gravimetry, 11 samples for 2-step combustion. Since the online instruments operate on different time resolutions, the data reduction was adjusted such that DMS500 and MAAP provided average data for respective filter sampling times while LII and EEPS provided data averaged over the entire condition run times. Data from CPC instruments were converted from $1 \mathrm{~Hz}$ to $15 \mathrm{~s}$ averages because this time resolution was met by all applied online instruments.

\section{RESULTS}

The exhaust aerosol is characterized by a trimodal size distribution. The number size distribution (Figure 1a) is dominated by one mode centered at $14-15 \mathrm{~nm}$ and a second mode centered at $47-59 \mathrm{~nm}$. For the volume size distribution (Figure $1 \mathrm{~b}$ ) the 


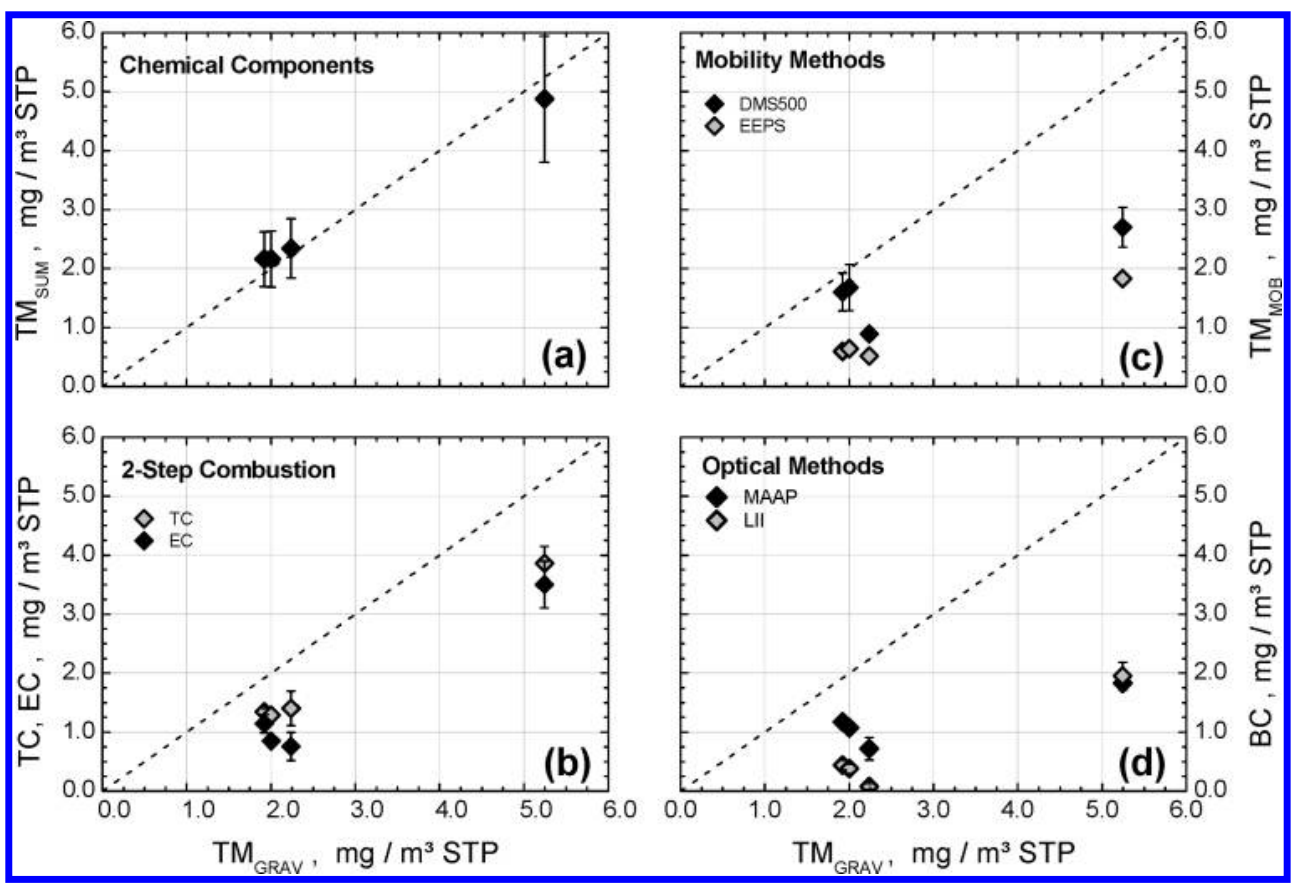

Figure 2. Condition-averaged mass concentration data for respective methods as a function of gravimetric values. Dashed lines indicate 1:1-relationship; error bars refer to $1-\sigma$ of the average $(\mathrm{STP}=273.15 \mathrm{~K}, 1013.25 \mathrm{hPa})$.

sub-20 nm mode is negligible, whereas a third mode centered at $320-420 \mathrm{~nm}$ contributes significantly. The size of emitted particles depends on operation conditions with particles being largest for high smoke conditions and being smallest for low smoke-low OM conditions. The chemical composition of the emitted PM is characterized by variable OC and EC fractions depending as well on the operation condition. The EC fraction of $\mathrm{TC}$ varies from $54 \%$ at condition $\mathrm{C} 2$ with high $\mathrm{OM}$ emissions to $91 \%$ at condition C3 with high smoke emissions, see also Table S2 of the SI and ref 10.

Mass measures are defined as follows: $\mathrm{TM}_{\mathrm{GRAV}}=$ total mass from gravimetry, $\mathrm{TM}_{\mathrm{SUM}}=$ total mass calculated from the sum of chemical components by eq $4, \mathrm{TM}_{\mathrm{MOB}}=$ total mass calculated from mobility spectra (DMS500, EEPS) assuming spherical particle shape and an effective particle density of $1000 \mathrm{~kg} \mathrm{~m}^{-3}$ for particles being composed of variable fractions of organic matter and elemental carbon. All mass-based methods are evaluated against the reference gravimetry $\mathrm{TM}_{\mathrm{GRAV}}$. Additionally, MAAP and LII are evaluated against 2-step combustion (EC) because they separate the light-absorbing carbonaceous fraction (BC) from TM. Data of two identical CPC are correlated for assessing the uncertainty in the measured data depending on instrument performance like variations in instrument flow and lower detection diameters. LII measures concentration directly and is independent of flow rate variations. The minimum detectable concentration for LII is approximately $1 \mu \mathrm{g} \mathrm{m}^{-3}$ but no known lower limit on particle size.

3.1. Mass-Based Techniques. Figure 2 compiles the mass concentrations obtained from the applied methods in relation to $\mathrm{TM}_{\mathrm{GRAV}}$ as reference method; numerical data are listed in Table S2 of the SI. Systematic trends are obvious: Mass closure between gravimetric mass and mass calculated from the sum of chemical components is achieved with $\mathrm{TM}_{\mathrm{SUM}}=(1.07 \pm 0.10) \times$ $\mathrm{TM}_{\mathrm{GRAV}}$ (Figure 2a). Neglecting adsorbed $\mathrm{H}_{2} \mathrm{O}$ results in $\mathrm{TM}_{\text {SUM-dry }}=(0.92 \pm 0.06) \times \mathrm{TM}_{\mathrm{GRAV}}$. TC is closely correlated

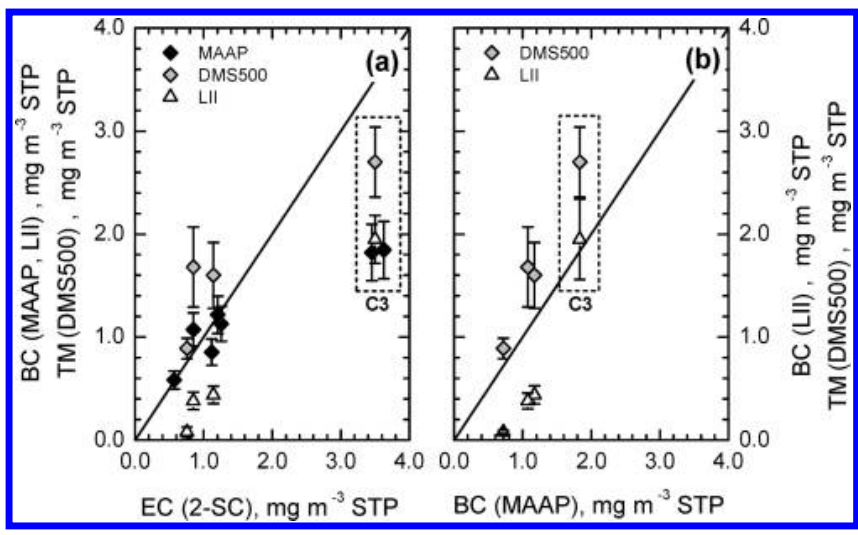

Figure 3. Intercomparison of mass-sensitive online methods; (a) mass concentrations measured by MAAP and LII for black carbon (BC) and DMS500 for total mass (TM) compared to elemental carbon (EC) from 2-step combustion representing filter-based methods; (b) TM (DMS500) and BC(LII) compared to BC(MAAP). Data from condition 3 (C3) are marked.

to $\mathrm{TM}_{\mathrm{GRAV}}$, but with a significant offset attributed to noncarbonaceous inorganic compounds (Figure 2b). Total mass calculated from size distributions underestimates total mass by $>35 \%$ on average (Figure 2c). EC from 2-step combustion (Figure 2b) and optical methods sensitive to light-absorbing BC (Figure 2d) are weakly correlated to $\mathrm{TM}_{\mathrm{GRAV}}$ while close correlation is found between $\mathrm{EC}$ and $\mathrm{BC}$.

The correlation between online methods MAAP, LII, and DMS500 and EC as a proxy for filter-based methods is shown in Figure 3. Close agreement is found between $\mathrm{BC}$ from absorption photometry (MAAP) and EC for conditions $\mathrm{C} 1$ and $\mathrm{C} 2$ with $\mathrm{BC}_{\text {MAAP }}=(1.08 \pm 0.16) \times \mathrm{EC}$. For condition $\mathrm{C} 3$ with the highest mass concentration values, all online methods deviate significantly but consistently from filter-based off-line methods 
Table 1. Average Number Concentrations Measured by the Different Cpc Systems and the DMS500 in the Raw Exhaust Gas; Data Presented As Number Concentration Values Given as $10^{7} \mathrm{~cm}^{3} \mathrm{STP}$ and as Results of a Linear Regression Analysis of Two Identical CPC Operated in Parallel

\begin{tabular}{|c|c|c|c|c|}
\hline & TSI $3760 \mathrm{~A} d_{\mathrm{p}, \min } \cong 14 \mathrm{~nm}$ & TSI $3010 d_{\mathrm{p}, \min } \cong 10 \mathrm{~nm}$ & GRIMM $5.400 d_{\mathrm{p}, \min } \cong 5 \mathrm{~nm}$ & DMS500 $d_{\mathrm{p}, \min } \cong 5 \mathrm{~nm}$ \\
\hline condition $\mathrm{C} 1, \mathrm{R} 1$ & 0.96 & 0.99 & 1.22 & $\mathrm{~N} / \mathrm{A}$ \\
\hline condition $\mathrm{C} 1, \mathrm{R} 2$ & 1.32 & 1.39 & 1.60 & 2.17 \\
\hline condition $\mathrm{C} 2$, sequence 1 & 2.79 & 2.91 & 3.61 & 3.40 \\
\hline condition $\mathrm{C} 2$, sequence 2 & 1.8 & 2.07 & 2.58 & $\mathrm{~N} / \mathrm{A}$ \\
\hline condition $\mathrm{C} 3$ & 1.86 & 1.89 & 2.14 & 1.92 \\
\hline Linear regression slope $\mathrm{m}$ & $0.920 \pm 0.001$ & $1.060 \pm 0.001$ & $1.011 \pm 0.002$ & $0.929 \pm 0.007$ \\
\hline correlation coefficient $\mathrm{r}^{2}$ & 0.996 & 0.990 & 0.891 & 0.988 \\
\hline ratio instrument no. 1 /instrument no. 2 & $0.925 \pm 0.077$ & $1.044 \pm 0.087$ & $1.013 \pm 0.036$ & $0.82-1.43$ \\
\hline
\end{tabular}

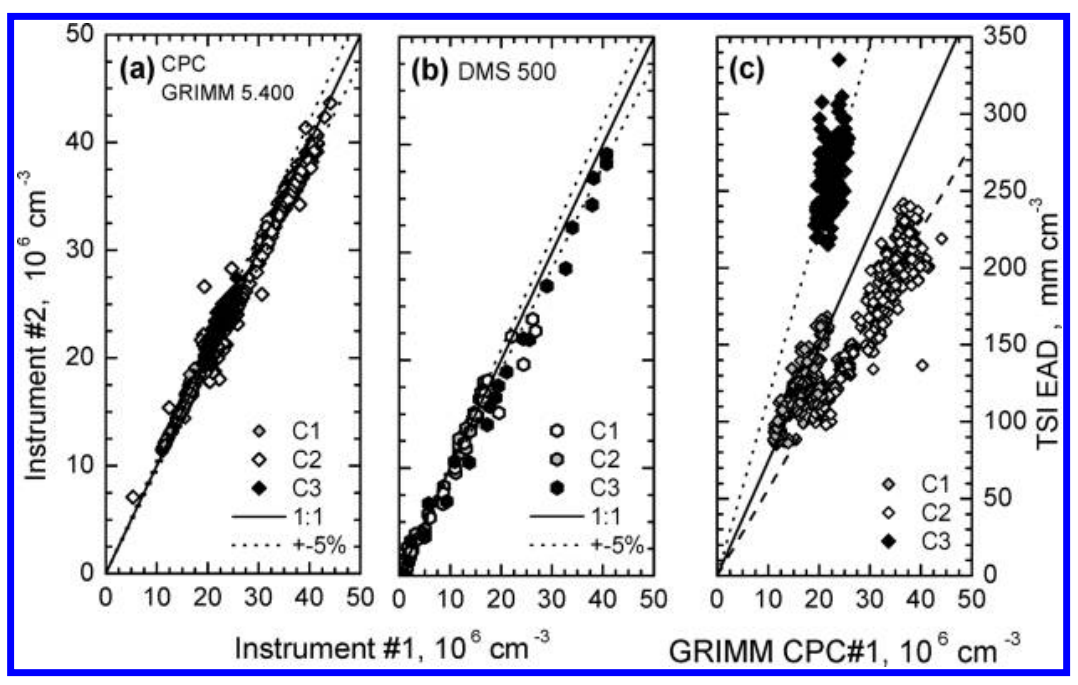

Figure 4. Correlation of two identical instruments (a) of CPC type GRIMM 5.400 and (b) of DMS500; (c) correlation of EAD type TSI 3070A and CPC GRIMM 5.400 for conditions C1-C3 separately.

(Figure 3a), whereas online methods are well correlated over the entire operation range (Figure $3 \mathrm{~b}$ ). Total mass from mobility data correlate well with $\mathrm{BC}$ from the MAAP with $\mathrm{TM}_{\mathrm{MOB}}=$ $(-0.29 \pm 0.27)+(1.64 \pm 0.05) \times \mathrm{BC}_{\mathrm{MAAP}}\left(r^{2}=0.99 ; 99 \%\right.$ significance). Higher $\mathrm{TM}_{\mathrm{MOB}}$ values compared to $\mathrm{BC}$ reflect the fact that size distributions contain also $\mathrm{OC}$ which is not detected by light-absorption methods. For the LII instrument, data are again correlated to $\mathrm{BC}_{\mathrm{MAAP}}$, but showing a significant negative bias. This bias requires further investigation.

Observed deviations of online and off-line methods for Condition C3 with the highest combustor load and resulting high sample flow and high mass concentration values are considered a sampling artifact. A detailed analysis of the LII signal (see SI) indicates the random occurrence of giant particles of $10 \mu \mathrm{m}$ in diameter and larger. These particles affect both gravimetry and $\mathrm{EC} / \mathrm{OC}$ analysis in the same way, but they are not sampled by online methods due to upper cutoff sizes in the inlet (DMS500), due to the fact that they occur only randomly (LII), or related to the fact that they do not contribute homogeneously to the filter loading of the MAAP.

For filter-based methods, reproducibility was taken from methods evaluations; see Section 2.2. Reproducibility of online optical methods LII and MAAP was not investigated but taken from separate studies conducted outside of SAMPLE. Reproducibility of the MAAP method was tested during an instrument intercomparison workshop yielding a relative standard deviation of $3 \%$ from the average $(1-\sigma) .{ }^{19}$ Comparative measurements for identical Artium LII-200 instruments were performed, investigating $\mathrm{BC}$ concentrations produced from a kerosene burner. There was a $1: 1$ correlation with less than $2 \%$ deviation for the majority of the data over the measured range of concentrations from less than $0.1 \mathrm{mg} \mathrm{m}^{-3}$ to over $10 \mathrm{mg} \mathrm{m}^{-3.29}$

3.1. Number-Based Methods. Three different models of CPC were operated in parallel in order to provide instrument intercomparison data. Results for the number-based instruments for the different conditions are compiled in Table 1. In addition, total number concentration of particles was derived from the DMS500. According to the different instrument $d_{\mathrm{p} \text {, min }}$ number concentrations appear in the order $\mathrm{N}($ DMS500) $\cong \mathrm{N}($ GRIMM $5.400)>\mathrm{N}($ TSI 3010) $>\mathrm{N}($ TSI 3760A $)$. Condition C2 was split into two sequences with different particle number concentrations.

Prior to each measurement the instrument bias of each CPC was tested with filtered air yielding number concentrations $<2.0 \mathrm{~cm}^{-3}$. Additionally, the maximum response function of all deployed CPC was tested applying an aerosol with $d_{\mathrm{p}}>30 \mathrm{~nm}$ by connecting diffusion screen separators ${ }^{30}$ upstream of the CPC. Obtained number concentrations for individual CPC instruments deviated by maximum $7 \%$ from the value averaged over all instruments. Differences between CPC are thus be attributed entirely to differences in $d_{\mathrm{p}}$, min. 
Table 2. Size Distribution Measurements Performed As Repetitive Measurements Using Two DMS500 Instruments (See Given Serial No.), or Determined from the Ratio of EAD vs. CPC Which Is Providing a Measure of Average Size

\begin{tabular}{|c|c|c|c|c|c|c|c|}
\hline \multicolumn{6}{|c|}{ DMS500 } & \multirow{2}{*}{\multicolumn{2}{|c|}{ EAD/CPC GRIMM 5.400}} \\
\hline & \multicolumn{2}{|c|}{ 1st mode } & \multicolumn{2}{|c|}{ 2nd mode } & \multirow[t]{2}{*}{ serial no. } & & \\
\hline & $\mathrm{CMD}(\mathrm{nm})$ & GSD & $\mathrm{CMD}(\mathrm{nm})$ & GSD & & ratio $(\mathrm{nm})$ & $r^{2}$ \\
\hline \multirow[t]{2}{*}{ condition $\mathrm{C} 1$} & 15.7 & 1.53 & 51.6 & 1.39 & M44 & $7.4 \pm 0.3$ & 0.733 \\
\hline & 15.8 & 1.54 & 50.0 & 1.41 & M45 & & \\
\hline \multirow[t]{2}{*}{ condition C2 } & 15.1 & 1.53 & 46.6 & 1.30 & M44 & $5.6 \pm 0.2$ & 0.880 \\
\hline & 14.1 & 1.54 & 46.9 & 1.32 & M44 & & \\
\hline condition C3 & 17.4 & 1.5 & 58.5 & 1.45 & M44 & $11.5 \pm 0.06$ & 0.263 \\
\hline
\end{tabular}

Figure 4 shows the scatter plots for CPC model GRIMM 5.400 (Figure 4a) and for the DMS500 (Figure 4b). All instruments based on the CPC technique show excellent reproducibility with a standard deviation of less than $5 \%$ in accordance with literature, ${ }^{23}$ with the exception of the TSI model 3060A which deviates by $7.5 \%{ }^{10}$ No effect of operation conditions or the organic content of PM is observed. The DMS500 instruments are also well correlated with an overall slope of the linear regression line of 0.93 . In contrast to CPC based instruments, the average ratio between the two instruments shows a substantially larger scatter and varies from 0.84 to 1.43 for different operation conditions.

3.3. Size-Based Methods. The data analysis of the differential mobility spectrometer is summarized in Table 2. Compiled are the count median diameter (CMD) and the geometric standard deviation (GSD) for two modes dominating number size distributions. These properties are defined on the basis of a bimodal log-normal size distribution. The reproducibility of particle size measurements is also shown in Table 2. Performing measurements in the same sampling line with two types of the DMS500 instruments yields relative standard deviations of measured $\mathrm{CMD}$ values of $<4 \%$.

The data from EAD and CPC are also highly correlated; see Figure 4c. The ratio of EAD to CPC which has the unit of an average particle diameter shows similar trends with condition as the CMD of the second mode of the mobility size spectrum. However, in accordance with ref 27 this method is not able to produce reliable particle size data, see Table 2 for details.

\section{DISCUSSION}

The consistent data set collected in SAMPLE from off-line and online mass-based methods permits an assessment of investigated methods with respect to their application for PM measurement in gas turbine exhaust. The focus on nonvolatile PM is in line with current understanding of particulate matter impacts on climate as well as on human health.

We achieved mass closure with the sum of key chemical components balancing total mass within 10\% deviation from gravimetry data. Carbonaceous matter makes up the largest fraction of PM mass with light-absorbing BC corresponding closely to nonvolatile EC. From that, robust light absorption measurement methods are potential candidates for online techniques sensitive to nonvolatile PM. Among those MAAP shows close agreement with EC while LII data indicate a systematic underestimation of $\mathrm{BC}$ compared to MAAP or EC from 2-step combustion. Total mass inferred from size distributions require major assumptions concerning particle shape and effective density for data inversion. Being aware of decreasing emission levels for future aircraft engines, methods of sufficient sensitivity at acceptable sampling times have to be considered. This requirement is met by the online methods tested here while gravimetry with sampling times of up to $45 \mathrm{~min}$ is ruled out.

Major discrepancies between online and off-line methods at high power condition are most likely related to sampling artifacts. These sampling issues are associated with the presence of supermicrometer-sized soot agglomerates which are suspected to originate from combustor surfaces including the spray nozzle, or from sample line abrasion. The use of a PM 1.0 cyclone or impactor prior to the filter sampling locations for eliminating these large agglomerates, will be studied in the next phase of SAMPLE in order to reduce sampling artifacts caused by large soot agglomerates.

CPC instruments proved highly robust tools for measuring aerosol number concentrations, characterized by a method precision of less than $7.5 \%$. Dilution of sample gas prior to the measurement is required. Absolute number concentrations given by different condensation particle counter models require careful consideration of the minimum detection diameter, defined for $50 \%$ detection efficiency. Indirect methods for the measurement of particle number concentrations as differential mobility spectrometry (DMS500, EEPS) are also capable of providing particle number concentration values, but direct methods like CPC are preferred because of much smaller scatter in data.

We recommend the measurement of nonvolatile particle number concentration by CPC-based methods with prior agreement on the instrument $d_{\mathrm{p}, \min }$ and the application of a volatile particle remover based on the hot dilution principle. Reproducibility with a standard deviation of less than $5 \%$ can be achieved. The method for measuring particle mass requires prior agreement of the measurand. For this particular source type, light absorbing BC and chemically inert and nonvolatile (for $T=$ $350{ }^{\circ} \mathrm{C}$ ) EC are almost equivalent. Potential techniques are optical-based methods for light-absorbing BC, and carbon burnoff methods for EC. Gravimetry as the only traceable method seems not appropriate because modern aircraft engines with low particle mass emissions require very long sampling times.

\section{ASSOCIATED CONTENT}

S Supporting Information. Additional information on instrumentation, hot end simulator, gas sample distribution system, dilution systems, evaluation of FOA3 for HES, mass measurement data, and supermicron particulates. This material is available free of charge via the Internet at http://pubs.acs.org. 


\section{AUTHOR INFORMATION}

\section{Corresponding Author}

*E-mail: andreas.petzold@dlr.de.

\section{ACKNOWLEDGMENT}

Part of this work was funded by the European Aviation Safety Agency (EASA) under contract no. EASA.2008.OP.13 and by the European Commission as part of ECATS (Environmentally Compatible Air Transport System) under contract no. ANE-CT2005-012284. We gratefully acknowledge the strong support by the team of the Gas Turbine Research Centre of Cardiff University during the tests.

\section{REFERENCES}

(1) Lee, D. S.; Pitari, G.; Grewe, V.; Gierens, K.; Penner, J. E.; Petzold, A.; Prather, M. J.; Schumann, U.; Bais, A.; Berntsen, T., et al. , Transport impacts on atmosphere and climate: Aviation. Atmos. Environ. 2010, 44, DOI: 10.1016/j.atmosenv.2009.06.005.

(2) SAE, AIR 6037: Aircraft Exhaust Nonvolatile Particle Matter Measurement Method Development. SAE Aerospace Information Report 2009.

(3) Petzold, A.; Fiebig, M.; Fritzsche, L.; Stein, C.; Schumann, U.; Wilson, C. W.; Hurley, C. D.; Arnold, F.; Katragkou, E.; Baltensperger, U.; et al. Particle emissions from aircraft engines - a survey of the European project PartEmis. Meteorol. Z. 2005, 14, 465-476.

(4) Kärcher, B.; Möhler, O.; DeMott, P. J.; Pechtl, S.; Yu, F. Insights into the role of soot aerosols in cirrus cloud formation. Atmos. Chem. Phys. 2007, 7, 4203-4227.

(5) Lobo, P.; Hagen, D. E.; Whitefield, P. D.; Alofs, D. J. Physical characterization of aerosol emissions from a commercial gas turbine engine. J. Propul. Power 2007, 23, 919-928.

(6) Herndon, S. C.; Jayne, J. T.; Lobo, P.; Onasch, T. B.; Fleming, G.; Hagen, D. E.; Whitefield, P. D.; Miake-Lye, R. C. Commercial aircraft engine emissions characterization of in-use aircraft at Hartsfield-Jackson Atlanta International Airport. Environ. Sci. Technol. 2008, 42, 1877-1883.

(7) Mazaheri, M.; Johnson, G. R.; Morawska, L. Particle and gaseous emissions from commercial aircraft at each stage of the landing and takeoff cycle. Environ. Sci. Technol. 2009, 43, 441-446.

(8) Aircraft gas turbine smoke measurement. In SAE Aerospace Recommended Practice, SAE, ARP 1179; Society of Automotive Engineers: Warrendale, PA, 1997.

(9) Nonvolatile exhaust particle measurement techniques. In $S A E$ Aerospace Information Report, SAE, AIR 5892; Society of Automotive Engineers: Warrendale, PA, 2004.

(10) Petzold, A.; Marsh, R.; Johnson, M.; Miller, M.; Sevcenco, Y.; Delhaye, D.; Vancassel, X.; Ibrahim, A.; Veira, A.; Williams, P., et al. Study on Sampling and Measurement of Aircraft Particulate Emissions SAMPLE-Final Report; EASA: Cologne, 2009; pp 139, http://www. easa.eu.int/ws_prod/r/doc/research/SAMPLE_Report_Final.pdf.

(11) Wilson, C. W.; Petzold, A.; Nyeki, S.; Schumann, U.; Zellner, R. Measurement and prediction of emissions of aerosols and gaseous precursors from gas turbine engines (PartEmis): an overview. Aerosp. Sci. Technol. 2004, 8, 131-143.

(12) Petzold, A.; Stein, C.; Nyeki, S.; Gysel, M.; Weingartner, E.; Baltensperger, U.; Giebl, H.; Hitzenberger, R.; Döpelheuer, A.; Vrchoticky, S., et al. , Properties of jet engine combustion particles during the PartEmis experiment: Microphysics and chemistry. Geophys. Res. Lett. 2003, 30, DOI: 10.1029/2003GL017283.

(13) Brown, A. S.; Yardley, R. E.; Quincey, P. G.; Butterfield, D. M. Ambient Air Particulate Matter: Quantifying Errors in Gravimetric Measurements, NPL Report DQL-AS 015; National Physical Laboratory: Teddington, UK, 2005; pp 41.

(14) Cachier, H.; Bremond, M. P.; Buat-Menard, P. Thermal separation of soot carbon. Aerosol Sci. Technol. 1989, 10, 358-364.
(15) Schmid, H.; Laskus, L.; Abraham, H. J.; Baltensperger, U.; Lavanchy, V.; Bizjak, M.; Burba, P.; Cachier, H.; Crow, D.; Chow, J.; et al. Results of the carbon conference international aerosol carbon round robin test stage I. Atmos. Environ. 2001, 35, 2111-2121.

(16) Aiken, A. C.; DeCarlo, P. F.; Kroll, J. H.; Worsnop, D. R.; Huffman, J. A.; Docherty, K. S.; Ulbrich, I. M.; Mohr, C.; Kimmel, J. R.; Sueper, D.; et al. O/C and OM/OC ratios of primary, secondary, and ambient organic aerosols with high-resolution time-of-flight aerosol mass spectrometry. Environ. Sci. Technol. 2008, 42, 4478-4485.

(17) Petzold, A.; Schönlinner, M. Multi-angle absorption photometry-A new method for the measurement of aerosol light absorption and atmospheric black carbon. J. Aerosol Sci. 2004, 35, 421-441.

(18) Bond, T. C.; Bergstrom, R. W. Light absorption by carbonaceous particles: An investigative review. Aerosol Sci. Technol. 2006, 40, 27-67.

(19) Müller, T.; Henzing, J. S.; Leeuw, G. d.; Wiedensohler, A.; Alastuey, A.; Angelov, H.; Bizjak, M.; Coen, M. C.; Engström, J. E.; Gruening, C.; et al. Characterization and intercomparison of aerosol absorption photometers: result of two intercomparison workshops. Atmos. Meas. Tech. 2011, 4, 245-268.

(20) Snelling, D. R.; Smallwood, G. J.; Liu, F.; Gülder, Ö. L.; Bachalo, W. D. A calibration-independent LII technique for soot measurement by detecting absolute light intensity. Appl. Opt. 2005, 44, 6773-6785.

(21) Wayson, R. L.; Fleming, G. G.; Iovinelli, R. Methodology to estimate particulate matter emissions from certified commercial aircraft engines. J. Air Waste Manage. Assoc. 2009, 59, 91-100.

(22) Petzold, A.; Weingartner, E.; Hasselbach, J.; Lauer, P.; Kurol, C.; Fleischer, F. Physical properties, chemical composition, and cloud forming potential of particulate emissions from a marine diesel engine at various load conditions. Environ. Sci. Technol. 2010, 44, 3800-3805.

(23) Giechaskiel, B.; Ntziachristos, L.; Samaras, Z. Effect of ejector dilutors on measurements of automotive exhaust gas aerosol size distributions. Meas. Sci. Technol. 2009, 20, 1-7.

(24) Hagen, D. E.; Lobo, P.; Whitefield, P. D.; Trueblood, M. B.; Alofs, D. J.; Schmid, O. Performance evaluation of a fast mobility-based particle spectrometer for aircraft exhaust. J. Propul. Power 2009, $25,628-634$.

(25) Symonds, J. P. R.; Reavell, K. S. J.; Olfert, J. S.; Campbell, B. W.; Swift, S. J. Diesel soot mass calculation in real-time with a differential mobility spectrometer. J. Aerosol Sci. 2007, 38, 52-68.

(26) Fissan, H.; Neumann, S.; Trampe, A.; Pui, D. Y. H.; Shin, W. G. Rationale and principle of an instrument measuring lung deposited nanoparticle surface area. J. Nanopart. Res. 2007, 9, 53-59.

(27) Frank, B. P.; Saltiel, S.; Hogrefe, O.; Grygas, J.; Garland Lala, G. Determination of mean particle size using the electrical aerosol detector and the condensation particle counter: Comparison with the scanning mobility particle sizer. J. Aerosol Sci. 2008, 39, 19-29.

(28) Li, L.; Chen, D. R.; Tsai, P. J. Use of an electrical aerosol detector $(\mathrm{EAD})$ for nanoparticle size distribution measurement. J. Nanopart. Res. 2009, 11, 111-120.

(29) Bachalo, W. D.; Sankar, S. V. Assessment of an Advanced Method for Measurement of the Solid Carbonaceous (Soot) Component of Mobile Source Particulate Matter; Grant no. 06-03, Final Report; California Air Resources Board: Sacramento, December 2009,2009.

(30) Feldpausch, P.; Fiebig, M.; Fritzsche, L.; Petzold, A. Measurement of ultrafine aerosol size distributions by a combination of diffusion screen separators and condensation particle counters. J. Aerosol Sci. 2006, 37, 577-597. 